\title{
Respiratory Embarrassment
}

Adam Possner, MD

General Internal Medicine, Medical Faculty Associates, George Washington University, Washington, DC, USA.

\section{Noun}

A state of being

characterized by

the signs of being

embarrassed, namely

rapid and shallow

breathing, blushing or

blanching of the skin

of the face and ears

diaphoresis

and palpitations.

Not to be confused

with feeling ashamed

of something you said

or chose not to say-

air that passed your lips

or that you held in-

out of anger or

fear or envy or

lack of empathy

although both of these

interpretations

may stem from one root

that being failure.

Corresponding Author: Adam Possner, MD, General Internal Medicine, Medical Faculty Associates, George Washington University, 2150 Pennsylvania Ave NW, Suite 5-416 North, Washington, DC 20037, USA (e-mail: apossner@mfa.gwu.edu). 